\title{
Growth Curves of Wild and Reintroduced Broad-Snouted Caimans (Caiman latirostris) and Their Management Implications
}

Authors: Viotto, Evangelina V., Navarro, Joaquín L., and Piña, Carlos I.

Source: South American Journal of Herpetology, 16(1) : 34-41

Published By: Brazilian Society of Herpetology

URL: https://doi.org/10.2994/SAJH-D-18-00077.1

BioOne Complete (complete.BioOne.org) is a full-text database of 200 subscribed and open-access titles in the biological, ecological, and environmental sciences published by nonprofit societies, associations, museums, institutions, and presses.

Your use of this PDF, the BioOne Complete website, and all posted and associated content indicates your acceptance of BioOne's Terms of Use, available at www.bioone.org/terms-of-use.

Usage of BioOne Complete content is strictly limited to personal, educational, and non - commercial use. Commercial inquiries or rights and permissions requests should be directed to the individual publisher as copyright holder.

BioOne sees sustainable scholarly publishing as an inherently collaborative enterprise connecting authors, nonprofit publishers, academic institutions, research libraries, and research funders in the common goal of maximizing access to critical research. 


\title{
Growth Curves of Wild and Reintroduced Broad-Snouted Caimans (Caiman latirostris) and Their Management Implications
}

\author{
Evangelina V. Viotto ${ }^{1,2}$, Joaquín L. Navarro ${ }^{3,4,5}$, Carlos I. Piña ${ }^{1,2,6, *}$ \\ ${ }^{1}$ Centro de Investigación Científica y de Transferencia Tecnológica a la Producción - Consejo Nacional de Investigaciones Científicas y Técnicas - Provincia de \\ Entre Ríos-Universidad Autónoma de Entre Ríos. Dr. Materi y España. CP 3105. Diamante, Entre Ríos, Argentina. \\ ${ }^{2}$ Proyecto Yacaré-Laboratorio de Zoología Aplicada: Anexo Vertebrados Facultad de Humanidades y Ciencias, Universidad Nacional del Litoral, Argentina. \\ ${ }^{3}$ Centro de Zoología Aplicada, Facultad de Ciencias Exactas, Físicas y Naturales, Universidad Nacional de Córdoba. Rondeau 798, CP 5000, Córdoba, Argentina. \\ ${ }^{4}$ Instituto de Diversidad y Ecología Animal-Consejo Nacional de Investigaciones Científicas y Técnicas y Universidad Nacional de Córdoba-Rondeau 798, \\ CP 5000, Córdoba, Argentina. \\ ${ }^{5}$ Cátedra de Problemática Ambiental. Departamento de Diversidad Biológica y Ecología Facultad de Ciencias Exactas, Físicas y Naturales, \\ Universidad Nacional de Córdoba. Av. Vélez Sarsfield 299, CP 5000 Córdoba, Argentina. \\ ${ }^{6}$ Facultad de Ciencia y Tecnología, Universidad Autónoma de Entre Ríos, Argentina. \\ * Corresponding author. Email: cidcarlos@infoaire.com.ar
}

\begin{abstract}
We describe body growth functions of broad-snouted caimans (Caiman latirostris) for wild and reintroduced individuals. Snoutvent length (SVL, $\mathrm{cm}$ ) and age of young individuals and adult females were recorded for two different groups: (Py) animals born in the Proyecto Yacaré ranching program, from eggs collected in the wild; and (Wy) wild caimans Class I ( $<25 \mathrm{~cm}$ SVL) whose age was determined by Size Frequency Analysis, plus females reintroduced by the Proyecto Yacaré and subsequently recaptured at reproductive age. To describe body growth, we adjusted five models through non-linear regression: Logistic, 4-Parameter Logistic (4-PL), Gompertz, 4-Parameter Gompertz (4-G), and von Bertalanffy. Each group was analyzed separately (Py and Wy), and we selected the most parsimonious model based on the Akaike criterion. We also analyzed the possible linear growth difference using ANCOVA. For Py, the Logistic model was best, whereas for Wy the most suitable was 4-PL, in which wild animals would arrive at the inflexion point 1.4 years later on average than in Py. Analyzing the stage at which their development was linear in shape, we detected that the wild animals had a similar growth rate to reintroduced individuals. As a result, although Py animals had experienced accelerated development whilst in captivity, it did not modify their subsequent growth in the wild. The likelihood of survival in this species increases with body size, thus it is important to emphasize that reintroduced animals are larger than wild animals of the same age and that previous farming conditions seem not to affect their growth in the wild. Therefore, we expect that reintroduced caimans will exhibit greater survivorship than natural animals of the same age. Consequently, an adjustment of the current ranching program should be considered, in the sense that population viability could be achieved by reintroducing a lower number of caimans each season.
\end{abstract}

Keywords. Growth models; Nonlinear regression; Ranching; Wild animals.

\section{INTRODUCTION}

Growth, survival, and reproduction are fundamental parameters in the life history of individuals and populations. Specifically in crocodilians, survival and reproduction are body-size dependent (Nichols et al., 1976; Hutton, 1987; Verdade, 2001; Larriera et al., 2004). Development in these animals is a complex process influenced by several factors, such as climatic conditions, resource availability within the habitat (food, shelter, sunbathing sites; Webb et al., 1978; Rootes et al., 1991; Tucker et al., 2006; Parachú Marcó et al., 2009; Silveira et al., 2013), sex (Webb et al., 1978; Hutton, 1987), genetics, incubation conditions (Piña et al., 2007), social factors (Lang, 1987), and even management practices (Piña and Larriera, 2002).
Growth patterns in reptiles can be adjusted by several theoretical models, like those presented by von Bertalanffy, Logistic, Gompertz and Richards, among others (Avery, 1994; Tucker et al., 2006; Rodríguez-Caro et al., 2013). In crocodilians, most studies use the von Bertalanffy model, building it with data from captures and recaptures, generally occurring at non-regular intervals (Campos et al., 2013; Silveira et al., 2013; Wilkinson et al., 2016). This procedure is commonly used as a consequence of both logistical difficulties in gathering the appropriate information and because individual crocodilians are longlived, thus a considerable accumulation of data is required for the estimations to have acceptable precision (Abercrombie and Verdade, 1992).

Sustainable use has become a common component of crocodilian conservation and management plans. Some

How to cite this article: Viotto E.V., Navarro J.L., Piña C.I. 2020. Growth curves of wild and reintroduced broad-snouted caimans (Caiman latirostris) and their management implications. South American Journal of Herpetology 16: 34-41. http://doi.org/10.2994/SAJH-D-18-00077.1

Submitted: 07 November 2018

Accepted: 24 May 2020

Available Online: 27 August 2020
Handling Editor: Pablo Siroski

http://doi.org/10.2994/SAJH-D-18-00077.1 
species are farm-raised, pursuing commercial or conservation objectives (Blake and Loveridge, 1975; Larriera and Imhof, 2006; Manolis and Webb, 2006). This strategy has proved to be successful in several cases (Dodd and Seigel, 1992), for example for Alligator mississisppiensis (Daudin, 1802) (Elsey et al., 1992, 2000), Crocodylus porosus Schneider, 1801 (Webb et al., 2000) and Crocodylus niloticus Laurenti, 1786 (Blake and Loveridge, 1975). The stability of crocodilian populations in the medium and long-term under well-conducted commercial harvest programs is a clear indicator of the appropriateness of this approach (Hutton and Webb, 2002; Hutton et al., 2002; Larriera and Imhof, 2006). In farms, animals are maintained at controlled temperatures and fed efficiently in order to accelerate growth (Larriera et al., 1990; Piña and Larriera, 2002; Larriera et al., 2008). Wild broad-snouted caiman populations in Argentina are subjected to a reinforcing strategy through a ranching system. In this system, complete clutches of wild nests are harvested, artificially incubated and then hatched. Hatchlings are farmed for 9 months before being returned to nature during the warm months at the same place from where the eggs were collected (Larriera and Imhof, 2006). Once in nature, these individuals are subjected to the same environmental pressures endured by wild-born animals, although when released they are larger than wild individuals of the same cohort. Previous data indicate that wild and reintroduced females exhibit similar size at the reproductive age (Portelinha, 2016).

The lack of information on the growth of either wild or reintroduced Caiman latirostris (Daudin, 1802) arouses interest in the development of these animals, particularly the fate of reintroduced individuals post-release (population reinforcement as defined by IUCN/SSC, 2013). The objective of this study was to describe and compare the growth of wild and reintroduced individuals of $C$. latirostris. From the obtained results, we aim to validate the assumption that ranching and release of reared individuals is an efficient strategy for fostering the population of this species. In this way, we hope to generate recommendations to ensure the viability of populations of this species in their natural habitat.

\section{MATERIALS AND METHODS}

We used data from captures obtained by Proyecto Yacaré from 1994-2016 in Santa Fe Province, Argentina. The study area includes floodplains and part of tributary rivers of the northwest of the province. It is characterized by numerous shallow lagoons, presents a gentle slope, and has slow drainage (Iriondo, 1985; Pautasso, 2003). Weather is temperate with marked seasonality and winter temperatures oscillating between $1-15^{\circ} \mathrm{C}$, with an average of $9^{\circ} \mathrm{C}$ (Universidad Nacional del Litoral, 2018).
To create growth curves, we used snout-vent length (SVL, $\mathrm{cm}$ ) and age (years) of individuals captured in warm months (October-March). Sex of broad-snouted caimans was determined through inspection of the cloaca for presence of a penis or clitoris (Piña et al., 2003, 2007). As this sexing method is only reliable beyond $35 \mathrm{~cm}$ SVL, depending on the species and observer experience (Ziegler and Olbort, 2007; Nuñez-Otaño et al., 2010; Combrink et al., 2012), individuals smaller than $35 \mathrm{~cm}$ were scored as "undetermined sex" (but see Ciocan et al. [2020] in this issue for sexing caimans). The data used for generating the model corresponded to immature individuals (Class I and II) and adult females. We eliminated male data because of their low frequency.

Data were classified into two groups, according to their origin. The group Py $(n=61)$ was composed of animals hatched from eggs collected in wildlife by the Ranching Program Proyecto Yacaré (Larriera and Imhof, 2006). For identification, these individuals were marked on their caudal scutes. They were raised in captivity, released into the sites where their nests were located, and later recaptured. In contrast, the group Wy $(n=140)$ was divided into three subgroups: wild-born Class I (CI; $<25 \mathrm{~cm} \mathrm{SVL}$, $n=109)$ individuals, Class II (CII; $\geq 25 \mathrm{~cm} \mathrm{SVL}, n=1)$ individuals, and the data of Py females at adult stage $(n=30)$. When a group of similar sized CI caimans were captured in the wild, we assumed they were from the same clutch and thus used their mean SVL as a single data point in our database. This prevented larger clutches having more leverage than single observations or clutches with fewer individuals. As such, we reduced 54 data points to 8 averages.

The age of Wy (those born in the wild) was estimated by the analysis of their size frequency using Gaussian Mixture Model from the "mixtools packages" (Benaglia et al., 2009; Fig. 1). We delimited three periods based on

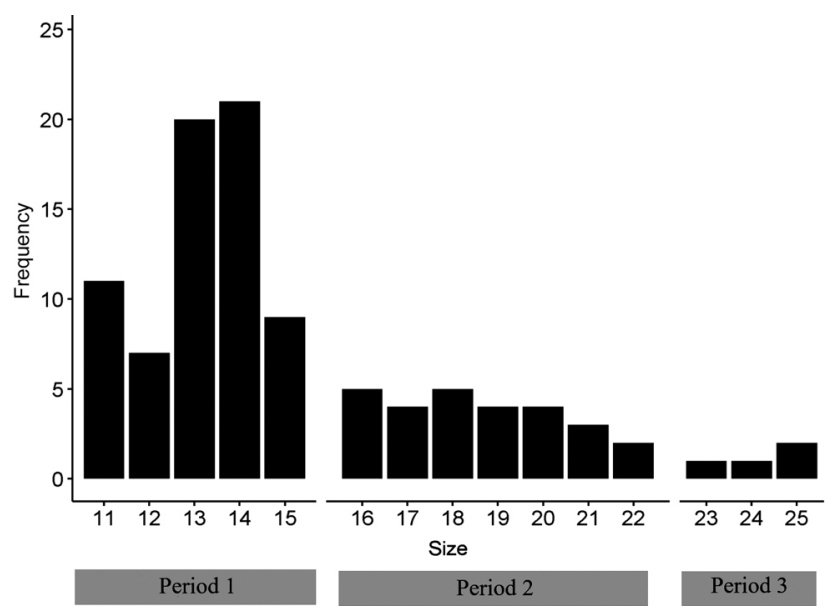

Figure 1. Histogram of the frequency distribution of snout-vent length (SVL, cm) of the captured wild caimans. The discontinuity in the graph shows the cut-off of the size that corresponds to each age in years, which was estimated through an analysis of size frequencies using Gaussian Mixture Model. 
the intersection point between the Gaussian curves (Period $1=10-15.4 \mathrm{~cm} \mathrm{SVL}$; Period 2 = > 15.4-23 cm SVL; and Period $3=>23-25 \mathrm{~cm} \mathrm{SVL}$ ). Every Wy classified in those periods was analyzed on the basis of the capture date (after or before hatching time) to determine if they belonged to the assigned period (each period corresponds to 1 year; i.e., Period 2 represents a 2 -year-old caiman). One Wy was captured and its age estimated to be $3.1 ; 0.9$ years later it was recaptured, so we used this animal in the database only in the $2^{\text {nd }}$ capture. In addition to these $\mathrm{CI}$ and CII specimens, we incorporated in the Wy group the data from 30 females raised and reintroduced by the Proyecto Yacaré (Py) that were recaptured 6-19 years later (thus of reproductive age). We included these adult females assuming that (a) any effect of captivity on their growth would have ceased due to the long period in the wild and (b) the asymptotic size would be the same between animals born in nature and the farm.

We tested five models of body growth by non-linear regression using the 'nlsr' package (Nash and Murdoch, 2017) in Rstudio (R Core Team, 2018), through an iterative process applying the Gauss-Newton algorithm. The models tested were Logistic, von Bertalanffy (VB), Gompertz (Dodd and Dreslik, 2008), 4-parameter Logistic (4$\mathrm{PL}, S V L=\frac{d}{\left(1+b \cdot e^{-k \text { Yea }}\right)}+\eta$, Logistics model plus constant $)$, and 4-parameter Gompertz (4-GL, SVL $=d \cdot e^{\left(b_{.} e^{-k \cdot Y e a r}\right)}+\eta$, Gompertz models plus constant). For every model, we evaluated the 'rate constant' $k$ (year ${ }^{-1}$ ), which determines $\frac{\ln (\mathrm{b})}{k}$ the spread of the curve along the time axis $(\beta=\bar{k}$, years), where the maximum growth occurs. For 4-PL and 4-GL, the constant $(\eta=\mathrm{cm})$ and the asymptotic size, such as $(\alpha=\eta+d, c m)$, were obtained.

We selected the model that best described variations of our data based on the maximum likelihood principle using the Akaike information criterion adjusted for small samples $\left(\mathrm{AIC}_{c}\right)$. We calculated difference in $\mathrm{AIC}_{c}$ between each model and the one with the lowest value. Later, we obtained $\mathrm{AIC}_{\mathrm{c}}$ 's normalized weight $\left(w_{i}\right)$ of each model, which allowed us to compare them to each other and select the most plausible one for our data $\left(0.6>w_{i}\right)$. Data considered to be outliers (their values were beyond two standard deviations from the value predicted by the model) were eliminated, and the model was rerun to obtain a less biased estimation. We used the Jackknife technique to measure the effect of each data on the average value of each parameter and to estimate the bias for each predicted value.

To evaluate if there was a difference in the initial growth pattern between both groups, we built a linear regression model with interaction. In this case, to test their correlation, we used only data corresponding to the linear growth interval (up to 4 years in Wy and from 9 months to 5 years in Py individuals). Because the covariate model did not comply with the homoscedasticity assumption, we analyzed it with Generalized Least Squares in the 'nlme' package (Pinheiro et al., 2017), using the maximum likelihood method. For this purpose, we built the combined variance function varComb(varIdent(form $=\sim 1 \mid$ Origin), $v$ $\operatorname{arExp}($ form $=\sim$ Time) $)$ and used graphic analyses to evaluate model assumptions.

\section{RESULTS}

The best model that described the growth of Py individuals was Logistic ( $w_{i}=0.6$, Table 1$)$, defined by: maximum SVL (asymptote) $\alpha=76.7 \pm 1.5 \mathrm{~cm}$ (bias $=0.08$ ), spread of the curve $\mathrm{k}=0.40 \pm 0.04$ year $^{-1}$ (bias $=0.0007$ ), and maximum growth at $\beta=3.1 \pm 0.4$ years (bias $=0.03$ ), with an SVL of $38.5 \mathrm{~cm}$ (Table 1). On the other hand, the best model for animals that completed their full development in nature (Wy) was the 4-PL $\left(w_{i}=0.96\right)$, with the following parameters: asymptote: $\alpha=75.05 \pm 1.8 \mathrm{~cm}, \mathrm{k}=0.68 \pm 0.04$ year $^{-1}$, maximum growth at $\beta=4.5 \pm 0.4$ years with SVL of $41.4 \mathrm{~cm}$, and constant $\eta=9.5 \pm 0.9$ (Fig. 2). The inter-

Table 1. Output of the five analyzed models. The best model for each group based on the Akaike information criteria is highlighted in grey. AIC : Akaike value; $\Delta \mathrm{AIC}_{c}$ : difference of the respective $\mathrm{AIC}_{c}$ with the lowest $\mathrm{AIC}_{c}$ value; $w_{i}$ : normalized weight; $\alpha$ : asymptotic size ( $\mathrm{cm}$ ); $\beta$ : inflexion point (years); $k$ : rate constant (year ${ }^{-1}$ ); and $\eta$ : constant; ${ }^{* *}$ Non-significant parameters.

\begin{tabular}{|c|c|c|c|c|c|c|c|}
\hline & \multicolumn{3}{|c|}{ Selection criteria } & \multicolumn{4}{|c|}{ Parameters } \\
\hline & Model & $\Delta \mathbf{A I C}_{c}$ & $W_{i}$ & $\alpha$ & $\boldsymbol{\beta}$ & $\boldsymbol{k}$ & $\eta$ \\
\hline \multirow[t]{5}{*}{$\overline{\mathbf{P y}}$} & Logistic & 0 & 0.6 & $76.7 \pm 1.5$ & $3.1 \pm 0.4$ & $0.4 \pm 0.04$ & - \\
\hline & LC & 2.3 & 0.2 & $73.7 \pm 12$ & $3.3 \pm 1.5^{* *}$ & $0.4 \pm 0.08$ & $-2.8 \pm 11.1^{* *}$ \\
\hline & Gompertz & 2.8 & 0.1 & $78.3 \pm 1.7$ & $1.64 \pm 0.3$ & $0.3 \pm 0.03$ & - \\
\hline & GC & 3.6 & 0.1 & $62.8 \pm 8.1$ & $3.3 \pm 1.3$ & $0.3 \pm 0.06$ & $14.3 \pm 7$ \\
\hline & VB & 9.9 & 0 & $81.5 \pm 2.6$ & $0.9 \pm 0.02$ & $0.18 \pm 0.02$ & - \\
\hline \multirow[t]{5}{*}{ Wy } & LC & 0 & 0.96 & $65.6 \pm 1.4$ & $4.5 \pm 0.4$ & $0.68 \pm 0.04$ & $9.45 \pm 0.9$ \\
\hline & GC & 13.6 & 0.04 & $62.3 \pm 1.3$ & $3.8 \pm 0.4$ & $0.5 \pm 0.04$ & $14.1 \pm 0.8$ \\
\hline & Logistic & 40.8 & 0 & $77.1 \pm 0.9$ & $4.0 \pm 0.2$ & $0.5 \pm 0.02$ & - \\
\hline & Gompertz & 79.3 & 0 & $79.9 \pm 1.3$ & $2.9 \pm 0.2$ & $0.32 \pm 0.01$ & - \\
\hline & VB & 110 & 0 & $89.2 \pm 4.1$ & 0 & $0.14 \pm 0.02$ & - \\
\hline
\end{tabular}




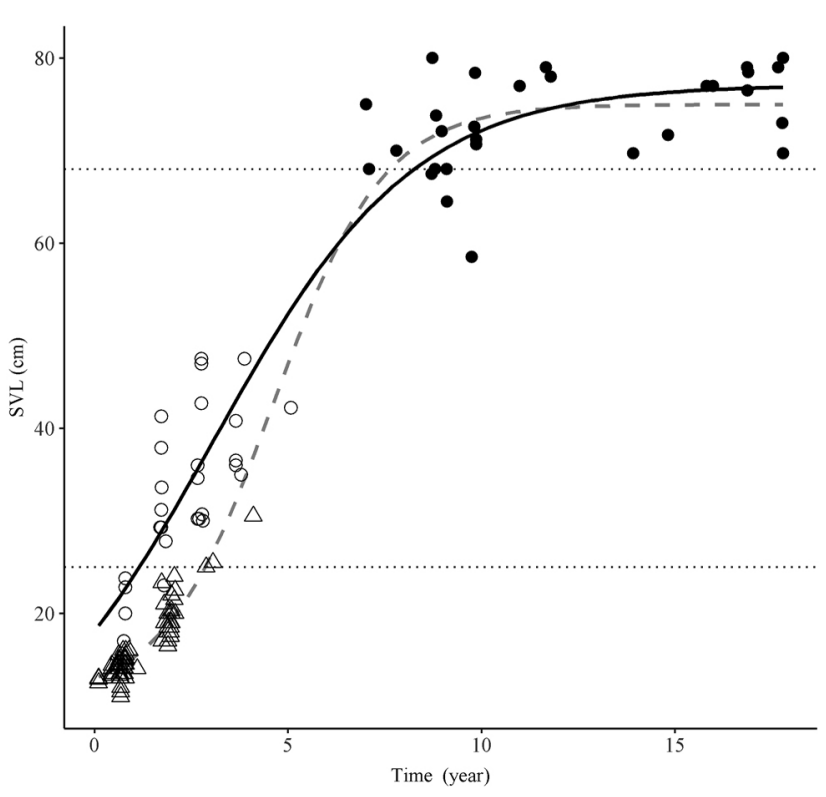

Figure 2. Non-linear models selected for each group of data of caimans. Dashed grey line: 4-PL Model, selected for Wy. Solid black line: Logistic Model selected for Py. Triangles: Wy Data; Circles: Py Data. Filled black circles: adult females of known age were used for curve fitting in both groups. The horizontal dotted lines depict the limits of the age class sizes as stated by Leiva et al. (2019).

section between the curves of both models occurred at 6.6 years old and $61.8 \mathrm{~cm}$ SVL. Thus, the start of Class III (CIII $68 \mathrm{~cm}$ SVL, Leiva et al., 2019) would be achieved for both groups at similar ages (about 7.9 years old).

In the period of linear growth, the covariate model showed that there was no interaction between the slopes according to the animals' origin $(P=0.1145)$. This shows that the linear growth rates of Py and Wy animals are the same, but individuals of Py are always larger (until the intersection of both curves). As a result, Py caimans are twice as large at the time of release (nine months of age) than those of Wy of the same age, and they reach $25 \mathrm{~cm} \mathrm{SVL}$ (CII) 0.3 years after reintroduction. On the other hand, wild caimans need 2.6 years to reach CII.

\section{DISCUSSION}

Our analysis allowed us to select the models that best described the growth of reintroduced and wild caimans, revealing that the growth of these two groups was different. We found that the Logistic model best described the growth of Py, whereas the best model for Wy was 4-PL (Table 1). Different species or even populations of the same species can differ in their growth patterns, because the best model for one data set might not be the best model for another one (Tucker et al., 2006). These discrepancies might reflect the distinct influence of the underlying local processes on growth (such as temperature, seasonality, and the quality and availability of food).
The models selected here are consistent with the best model for Alligator mississippiensis in Louisiana (Elsey et al., 1992). That study used data from reintroduced and wild juveniles of known age, and we used animals of know age (individuals $\mathrm{Py}$ ) or age estimated independently of the selected model (in our case using frequency analysis for Wy group). This approach differs from the one used in most works published previously (e.g., Caiman latirostris: Moulton et al., 1999; A. mississippiensis: Brisbin, 1988; Rootes et al., 1991; Wilkinson and Rhodes, 1997; Wilkinson et al., 2016; Melanosuchus niger [Spix, 1824]: Silveira et al., 2013; Paleosuchus palpebrosus [Cuvier, 1807]: Campos et al., 2013; Crocodylus johnstoni Krefft, 1873: Tucker et al., 2006; and Crocodylus niloticus: Hutton, 1987). Unlike those studies, the fact that the estimation of ages in our study was obtained independently from the model gives our approach an advantage at the time of decision making. Moulton et al. (1999) warned that ages obtained through models should be handled with caution when trying to predict certain specific characteristics of a population. This advantage is maintained despite the fact that in our data there is a gap in the intermediate zone of the curve, which can generate bias in the estimates of the model.

Another potential source of bias in this study could be the imbalance in the sample size of the components Wy data, and fundamentally the fact of the heterogeneous origin of our data as, on the one hand, Wy is composed of modeled data (from size frequency analysis; $C I=158, C I I=1)$ and, on the other, data from adult females of known age (CIII $=30$ released from Py) are also used. In this sense, the modeled data show less dispersion than those of animals of known ages, so that the former might not represent all the variability of the species in that period of its life history. The reduced dispersion is present not only within Wy individuals of other classes, but also between Py and Wy of small size (Classes I and II; Fig. 2). Despite its weaknesses, using data from different origins to generate growth models has, as a counterpart, the advantage that it allows adding information that a single data source alone does not usually provide. In other words, when one set of data is somehow deficient, another can provide valuable complementary information (Eveson et al., 2004). Appealing to this alternative might be indispensable to obtain at least a first approximation to address a problem using an adaptive management scheme that, as new information is progressively generated, reduces the initial uncertainties in the decision making process.

Some authors state that asymptotic sizes obtained by growth models should not be interpreted as the maximum size that individuals could reach in the population but rather indicate the average value at which growth ceases in most individuals (Wilkinson and Rhodes, 1997; Tucker et al., 2006; Wilkinson et al., 2016). The com- 
parison of the asymptotic value obtained in the Py model $(\alpha=76.7 \pm 1.5 \mathrm{~cm})$ vs. that of wild reproductive females $(\bar{x}=81.4 \pm 11.8 \mathrm{~cm}$, average calculated based on the years that only presented wildlife data reported by Leiva et al., 2019) suggests that the maximum size obtained by us with the Logistic model is similar to that of wild animals. Furthermore, the von Bertalanffy model reaches an asymptotic value of $94 \pm 1.8 \mathrm{~cm}$ (Moulton et al., 1999) that is similar to what Bertalanffy predicts for Py (Table 1 ). However, this model, which exhibited the highest asymptotic value, is has the poorest fit to our data among all those tested here.

Growth dynamics of crocodilians are influenced more by the age at which first reproduction occurs than by the asymptotic size (Brisbin, 1988). Minimum reported reproductive size is $68 \mathrm{~cm}$ SVL for wild females (Portelinha et al., 2015) and $69 \mathrm{~cm}$ for reintroduced females (Larriera et al., 2006), the latter at 7.9 years old. Using our model, we can estimate the minimum reproductive age as $8.1 \pm 1.8$ years, similar to that found by Moulton et al. (1999) in Brazil, where caimans would begin to reproduce at $75 \mathrm{~cm}$, age 8.6 years. Likewise, the minimum reported age of reproduction in captivity is 5 years (81 cm from SVL; Verdade et al., 2003), these females being larger than the reported wild ones. By achieving the necessary size earlier, females with more available resources could reproduce at a younger age. Therefore, females with more available resources could reproduce at a younger age because they grow faster and thus achieve the required size earlier. However, they might need to reach both a threshold size and age to be able to reproduce. Wilkinson et al. (2016) state that the optimal strategy for females might be to grow relatively rapidly to attain a size where chances of predation decrease and then shift substantial amounts of energy to reproduction and maintenance. In the studied populations, it looks like the growth of the females, rather than their age, would be the bottleneck to successfully achieve their first reproduction.

As the selected models are different, it is not possible to compare the growth change of $\mathrm{Wy}$ and $\mathrm{Py}$. This parameter is strongly influenced by the asymptotic value and the minimum size used to build the models. Consequently, to avoid any bias of this type, it was necessary to analyze the phase of linear growth separately. In the linear phase of development (growth at Classes I and II), we detected that the absolute increase in SVL of wild animals did not differ significantly from that of reintroduced animals, but it started at a different initial size (Fig. 3). Similar conservation projects in other species have reported a similar growth or in some cases, a greater growth, for instance, in released Alligator mississippiensis in Louisiana (Elsey et al., 1992). In contrast, in Crocodylus niloticus the growth of reintroduced animals is lower than that of wild individuals (Blake and Loveridge, 1975).
Our analysis allows us to estimate that at the time of reintroduction (approximately 9 months of age), a Py animal achieves a size which is equivalent to that of a 2.6-year-old Wy and reaches the maximum growth point 1.4 years earlier. As the absolute growth of the Py caimans after their release is similar to that of $\mathrm{Wy}$, we can conclude that their passage through captive conditions does not jeopardize their development in the wild. Furthermore, because survival in crocodilians is size dependent (Somaweera et al., 2013), remaining less time in the size Class I, which has the highest mortality, gives an advantage to the animals reintroduced by Proyecto Yacaré and, consequently, they should exhibit lower mortality than wild animals of the same age. Thus, we can affirm that the ranching program seems to be accomplishing its objective of fostering the caiman population.

Long-term studies of this species have shown that the release of captive-bred caimans is also a feasible management, and there is evidence that it is beneficial for the population's recovery. For example, since this approach was implemented in Argentina, the number of nests has progressively increased (Larriera and Imhof, 2006; Larriera et al., 2006; Leiva et al., 2019). Results obtained in this study support the idea that this method of ranching benefits wild populations of caimans. The benefit arises because the growth of ranched animals after being reintroduced is equal to that of wild animals of the same age,

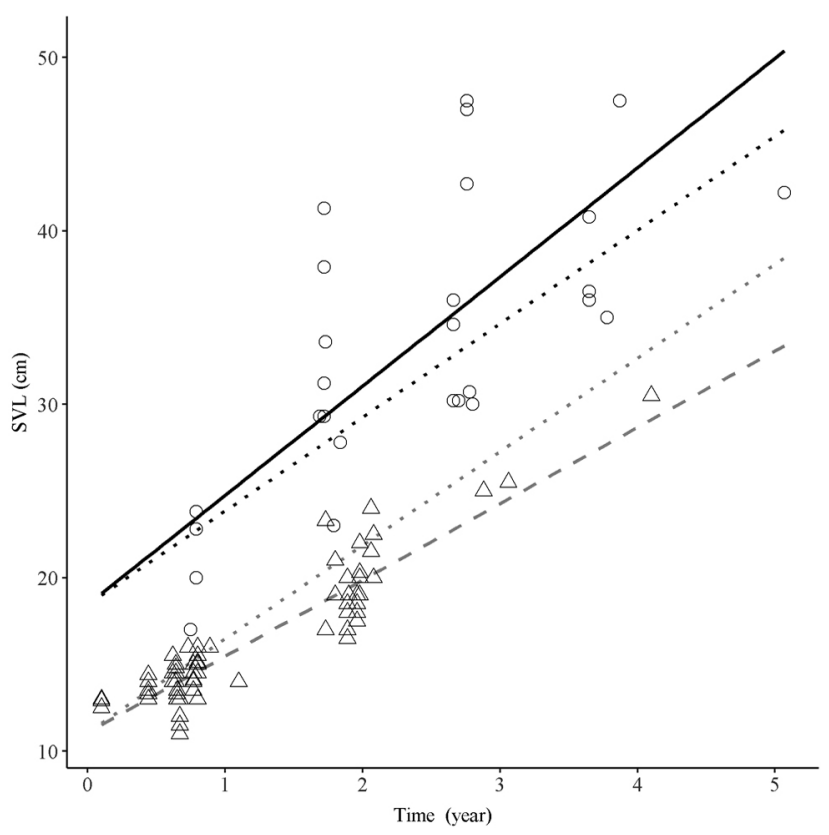

Figure 3. Growth during the first years in the wild of reintroduced caiman (grey) and wild caiman (black). Solid line represents lineal function for reintroduced (Py) animals (snout-vent length [SVL] $\mathrm{Py}_{\mathrm{y}}=6.3$ years $+18.4 \mathrm{~cm}$ ); gray dashed line represents lineal function for wild $(\mathrm{Wy})$ animals $\left(\mathrm{SVL}_{W_{y}}=4.6\right.$ years $\left.+10.9 \mathrm{~cm}\right)$. Slope of both lines are similar (slope: $\mathrm{T}=-1.59, P=0.1145$ ). Dotted lines represent those produced with the mean slope of the original functions (black for Py,

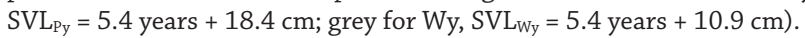


but they are larger than wild conspecifics of the same age. It takes Wy longer to reach the size of Py because they face a more rigorous environment during the first winter in wild conditions. Wy individuals also have higher predation risk during their early stages of development. Therefore, the reintroduced animals have a higher probability of survival than the wild animals of the same age.

Our data indicate that a Wy needs 2.6 years to reach CII (when mortality will be reduced), whereas a Py reintroduced caiman would need only 0.3 years in the wild to reach CII. If we consider that mortality during CI is independent of caiman size, released caimans will have higher chances to reach CII than Wy as it would take only 0.3 years to be $25 \mathrm{~cm}$ SVL. Our results could have implications for the necessary number of caimans to reintroduce for ensuring population viability. To estimate the number of animals to be released, we can think of a scenario in the wild in which 30 nests with an average clutch size of 35 eggs (Simoncini et al., 2009) would produce 1,050 eggs. During incubation, $35 \%$ of those nests could be lost, resulting in 682 hatchlings; but this estimation seems to be a conservative number based on: $50-62 \%$ of the nests predated (Deitz and Hines 1980), up to $41 \%$ in dry years (Larriera and Piña 2000), and $28.5 \%$ lost only by colony of red imported fire ants in nests of $C$. latirostris (Parachú Marcó et al., 2015). Data from Proyecto Yacaré indicate that approximately $10 \%$ of the hatchlings survive their first year (Viotto et al., unpublished results), and we can assume that $30 \%$ of the survivors would reach CII. This means that from the 682 hatchlings, 20 caimans would reach CII. On the basis of previous data (Nichols et al., 1976; Woodward et al., 1987; Wood et al., 2017), we consider that our scenario is conservative and that a lower percentage of caimans would reach CII.

In contrast, Proyecto Yacaré reintroduces $10 \%$ of the harvested nests (to be included in the reintroduction group, the nest must have at least 35 hatchlings). In the same scenario of 30 nests harvested from one place, the program selects three nests (at least 105 hatchlings) that will produce at least 70 animals for reintroduction $(23 \mathrm{~cm}$ SVL on average), which is approximately three times more hatchlings than those produced from 30 nests reaching CII (25 cm SVL) in wild conditions. We estimate that a 5\% reintroduction (instead of the $10 \%$ currently being released by Proyecto Yacaré) would be closer to natural survivorship.

Models are simplified approximations of a complex reality that contains many unknown factors, so they should always be interpreted with caution when bringing them to reality. For this reason, in order to avoid endangering the animal populations involved, it is necessary to implement adequate monitoring and control mechanisms. In the case of the broad-snouted caiman, if it were decided to reduce the number of released young, as we suggest, it would also be necessary to carry out studies over a longer term, in an experimental way, and accompanied by systematic monitoring. This would enable researchers to evaluate whether or not the proposed and implemented release percentages are adequate for the maintenance of the structure and abundance of the caiman population under the existing environmental scenario and the permitted conditions of use.

\section{ACKNOWLEDGMENTS}

We thank all the members of Proyecto Yacaré for providing data and assistance during fieldwork, G. González (IDEA, CONICET-UNC) for helping in the preparation of figures, and G.M. Giacone and Charlotte Smith for checking the English style. E. Viotto is a doctoral fellow of CONICET at CICyTTP (CONICET-Prov. Entre Ríos-UAdER). This study was supported by Proyecto Yacaré, Yacarés Santafesinos (Gob. Prov. Santa Fe/MUPCN), PFIP 2008; and PICT 2014 N2138 (to C. Piña), PICT 2014 N2212 (to M. Simoncini). We thank the three reviewers for the comments that improved the earlier version of this work. This is the $106^{\text {th }}$ publication of Proyecto Yacaré.

\section{REFERENCES}

Abercrombie C.L., Verdade L.M. 1992. A análise do crescimento em crocodilianos. Pp. 1-20, in Verdade L.M., Larriera A. (Eds.), La Conservación y el Manejo de Caimanes y Cocodrilos de América Latina, Vol. 2. C.N. Editoria, Piracicaba.

Avery R.A. 1994. Growth in reptiles. Gerontology 40:193-199. DOI

Benaglia T., Chauveau D., Hunter D.R., Young D. 2009. Mixtools: An R package for analyzing finite mixture models. Journal of Statistical Software 32:1-29.

Blake D.K., Loveridge J.P. 1975. The role of commercial crocodile farming in crocodile conservation. Biological Conservation 8:261272. DOI

Brisbin I.L. Jr. 1988. Growth curve analyses and their application to the conservation and captive management of crocodilians. Pp. 116145 , in Crocodile Specialist Group IUCN (Eds.), Proceedings of the $9^{\text {th }}$ Working Meeting of the Crocodile Specialist Group-IUCN, Gland.

Campos Z., Magnusson W.E., Marques V. 2013. Growth rates of $\mathrm{Pa}$ leosuchus palpebrosus at the southern limit of its range. Herpetologica 69:405-410. DOI

Ciocan H., Leiva P.M.L., Simoncini M.S. 2020. Sexual identification of Caiman latirostris hatchlings by cloacal inspection. South American Journal of Herpetology. In press.

Combrink X., Warner J.K., Hofmeyr M., Govender D., Ferreira S.M. 2012. Standard operating procedure for the monitoring, capture and sampling of Nile crocodiles (Crocodylus niloticus). Pp. 1-4, in Swan G. (Ed.), South African National Parks, Skukuza.

Cuvier G. 1807. Sur les différentes espèces de crocodilies vivans et sur leurs caractères distinctifs. Annales Muséum National D'Histoire Naturelle 10:8-86.

Daudin F.M. 1802 Histoire Naturelle, Générale et Particulière des Reptiles; ouvrage faisant suite à l'Histoire naturelle générale et particulière, composée par Leclerc de Buffon; et rédigée par C.S. Sonnini, membre de plusieurs sociétés savantes, Tome 2. F. Dufart, Paris. DOI

Deitz D.C., Hines T.C. 1980. Alligator nesting in north-central Florida. Copeia 1980:249-258. DOI

Dodd C.K. Jr., Dreslik M.J. 2008. Habitat disturbances differentially affect individual growth rates in a long-lived turtle. Journal of Zoology 275:18-25. DOI 
Dodd C.K. Jr., Seigel R.A. 1992. Relocation, repatriation, and translocation of amphibians and reptiles: are they conservation strategies that work? Herpetologica 47:336-350.

Elsey R.M., Joanen T.E.D., McNease L., Kinler N. 1992. Growth rates and body condition factors of Alligator mississippiensis in coastal Louisiana wetlands: a comparison of wild and farm-released juveniles. Comparative Biochemistry and Physiology Part A: Physiology 103:667672. DOI

Elsey R.M., McNease L., Joanen T. 2000. Louisiana's alligator ranching program: A review and analysis of releases of captive-raised juveniles. Pp. 426-442, in Grigg G.C., Seebacher F., Franklin C.F. (Eds.), Crocodilian Biology and Evolution. Surrey Beatty, Chipping Norton.

Eveson J.P., Laslett G.M., Polacheck T. 2004. An integrated model for growth incorporating tag-recapture, length-frequency, and direct aging data. Canadian Journal of Fisheries and Aquatic Sciences 61:292306. DOI

Hutton J.M. 1987. Growth and feeding ecology of the Nile crocodile Crocodylus niloticus at Ngezi, Zimbabwe. Journal of Animal Ecology 56:25-38. DOI

Hutton J., Webb G.W. 2002. Legal trade snaps back: using the experience of crocodilians in draw lessons on regulation of the wildlife trade. Pp. 1-18., in Crocodile Specialist Group IUCN (Eds.), Proceedings of the $9^{\text {th }}$ Working Meeting of the Crocodile Specialist Group-IUCN, Gland.

Hutton J.M., Ross P., Webb G. 2002. Using the market to create incentives for the conservation of crocodilians: a review. Pp. 382-399, in Crocodile Specialist Group IUCN (Eds.). Proceedings of the $16^{\text {th }}$ Working Meeting of the CSG-IUCN - The World Conservation Union, Gland.

Iriondo M.H. 1985. Geología y geomorfología, su importancia y relación con la edafología. INTA, Estación Experimental Regional Agropecuaria Rafaela, Publicación Miscelánea 30:143-186.

IUCN/SSC 2013. Guidelines for Reintroductions and Other Conservation Translocations, Version 1.0. IUCN Species Survival Commission, Gland.

Krefft G. 1873. Remarks on Australian crocodiles, and description of a new species. Proceedings of the Zoological Society of London 1837:334335.

Lang J.W. 1987. Crocodilian behavior: implications for management. Pp. 273-294, in Webb G.J.W., Manolis S.C., Whitehead P.J. (Eds.), Wildlife Management: Crocodiles and Alligators. Surrey Beatty \& Sons, Sydney.

Larriera A., Imhof A. 2006. Proyecto Yacaré. Pp. 51-64, in Bolkovicy M.L., Ramadori D. (Eds.), Manejo de Fauna Silvestre en Argentina. Ministerio de Salud y Ambiente de la Nación, Buenos Aires.

Larriera A., Piña C. 2000. Caiman latirostris (broad-snouted caiman) nest predation: does low rainfall facilitate predator access? Herpetological Natural History 7:73-77.

Larriera A., Aguinaga M., Del Barco D. 1990. Observaciones sobre el crecimiento de Caiman latirostris (Daudin, 1802), a diferentes temperaturas (Crocodylia: Alligatoridae). Amphibia Reptilia 1:115-117.

Larriera A., Piña C.I., Siroski P., Verdade L.M. 2004. Allometry of reproduction in wild broad-snouted Caimans (Caiman latirostris). Journal of Herpetology 38:301-304. DOI

Larriera A., Siroski P., Piña C.I., Imhof A. 2006. Sexual maturity of farm-released Caiman latirostris (Crocodylia: Allitoridae) in the wild. Herpetological Review 37:26-28.

Larriera A., Imhof A., Siroski P. 2008. Estado actual de los programas de conservación y manejo del género Caiman en Argentina. Pp. 143179, in Castroviejo J., Ayarzaguena J., Velasco A. (Eds), Construcción al Conocimiento de los Caimanes del Género Caiman de Sudamérica. Associacíon Amigos de Doña Ana, Sevilla.

Laurenti J.N. 1768. Specimen medicum, exhibens synopsin reptilium emendatam cum experimentis circa venena et antidota reptilium austriacorum. Joan. Thom. Nob. de Trattern, Viennae. DOI

Leiva P.M.L., Simoncini M.S., Portelinha T.C.G., Larriera A., Piña C.I. 2019. Size of nesting female Broad-snouted caimans (Caiman latirostris Daudin 1802). Brazilian Journal of Biology 79:139-143. DOI
Manolis S.C., Webb G.J.W. 2006. Best Management Practices for Crocodilian Farming, Version 1. IUCN - Crocodile Specialist Group, Karama.

Moulton T.P., Magnusson W.E., Tereza M., Queiroz Melo M.T. 1999. Growth of Caiman latirostris inhabiting a coastal environment in Brazil. Journal of Herpetology 33:479-484. DOI

Nash J.C., Murdoch D. 2017. nlsr: Functions for Nonlinear Least Squares Solutions. R package Version 2017.10.4. Available from: https://CRAN.R-project.org/package=nlsr.

Nichols J.D., Viehman L., Chabreck R.H., Fenderson B. 1976. Simulation of a commercially harvested Alligator population in Louisiana. LSU Agricultural Experiment Station Reports 470. Available from: http://digitalcommons.lsu.edu/agexp/470.

Nuñez-Otaño N.B., Imhof A., Bolcatto P.G., Larriera A. 2010. Sex differences in the genitalia of hatchling Caiman latirostris. Herpetological Review 41:32-35.

Parachú Marcó M.V., Piña C.I., Larriera A. 2009. Food conversion rate (FCR) in Caiman latirostris resulted more efficient at higher temperatures. Interciencia 34:428-431.

Parachú Marcó M.V., Larriera A., Piña C.I. 2015. Red fire ant (Solenopsis invicta) effects on broad-snouted Caiman (Caiman latirostris) nest success. Journal of Herpetology 49:70-74. DOI

Pautasso A.A. 2003. Aprovechamiento de la fauna silvestre por los pobladores rurales en la fracción norte de los Bajos Submeridionales de la provincia de Santa Fe, Argentina. (Incluye aspectos relacionados a la producción y la conservación en este ambiente). Comunicaciones del Museo Provincial de Ciencias Naturales Florentino Ameghino 8:1-62.

Piña C.I., Larriera A. 2002. Caiman latirostris growth: the effect of a management technique on the supplied temperature. Aquaculture 211:387-392. DOI

Piña C.I., Larriera A., Cabrera M.R. 2003. Effect of incubation temperature on incubation period, sex ratio, hatching success, and survivorship in Caiman latirostris (Crocodylia, Alligatoridae). Journal of Herpetology 37:199-202. DOI

Piña C.I., Larriera A., Medina M., Webb G.J.W. 2007. Effects of incubation temperature on the size of Caiman latirostris (Crocodylia: Alligatoridae) at hatching after one year. Journal of Herpetology 41:205210. DOI

Pinheiro J., Bates D., Deb Roy S., Sarkar D., R Core Team. 2017. nlme: Linear and nonlinear mixed effects models. R package. Available from: https://CRAN.R-project.org/package=nlme.

Portelinha T.C.G. 2016. Área de vida, uso de hábitat y ciclo reproductivo de Caiman latirostris (Crocodylia, Alligatoridae) en la provincia de Santa Fe, Argentina. Ph.D. Dissertation, Universidad Nacional de Córdoba, Argentina.

Portelinha T.C.G., Jahn G.A., Hapon M.B., Verdade L.M., Piña C.I. 2015. Hormone levels and ultrasound evaluation of Caiman latirostris (Crocodylia, Alligatoridae) ovulation. South American Journal of Herpetology 10:23-31. DOI

R Core Team. 2018. R: A language and environment for statistical computing, Version 3.4.4. Available from: https://www.R-project.org.

Rodríguez-Caro R.C., Graciá E., Anadón J.D., Gimenez A. 2013. Maintained effects of fire on individual growth and survival rates in a spur thighed tortoise population. European Journal of Wildlife Research 59:911-913. DOI

Rootes W.L., Chabreck R.H., Wright V.L., Brown B.W., Hess T.J. 1991. Growth rates of American alligators in estuarine and palustrine wetlands in Louisiana. Estuaries 14:489. DOI

Schneider J.G. 1801. Historiae Amphibiorum naturalis et literariae. Fasciculus secundus continens Crocodilos, Scincos, Chamaesauras, Boas, Pseudoboas, Elapes, Angues, Amphisbaenas et Caecilias. Fried. Frommann, Jenae. DOI

Silveira R., Campos Z., Thorbjarnarson J., Magnusson W.E. 2013. Growth rates of black caiman (Melanosuchus niger) spectacled caiman (Caiman crocodilus) from two different Amazonian flooded habitats. Amphibia-Reptilia 34:437-449. DOI

Simoncini M.S., Piña C.I., Siroski P.A. 2009. Clutch size of Caiman latirostris (Crocodylia: Alligatoridae) varies on a latitudinal gradient. North-Western Journal of Zoology 5:191-196. 
Somaweera R., Brien M., Shine R. 2013. The role of predation in shaping crocodilian natural history. Herpetological Monographs 27:2351. DOI

Spix J.B.v. 1824. Animalia nova sive species novae Lacertarum quas in itinere per Brasiliam annis MDCCCXVII-MDCCCXX jussu et auspicius Maximiliani Josephi I Bavariae Regis. F.S. Hübschmanni, Monachii. DOI

Tucker A.D., Colin J.L., Keith R.M., McCallum H.I. 2006. Growth dynamics of freshwater crocodiles (Crocodylus johnstoni) in the Lynd River, Queensland. Australian Journal of Zoology 54:409-415. DOI

Universidad Nacional del Litoral. 2018. Santa Fe, Clima. Accessible at www.unl.edu.ar/santafe/index.php/geografia/clima.html. Accessed: 18 October 2018.

Verdade L.M. 2001. Allometry of reproduction in broad-snouted caiman (Caiman latirostris). Brazilian Journal of Biology 61:431-435. DOI

Verdade L.M., Sarkis-Goncalves F., Miranda-Vilela M.P., Bassetti L.A.B. 2003. New record of age at sexual maturity in captivity for Caiman latirostris (Broad- Snouted Caiman). Herpetological Review 34:225-226.

Webb G.J.W., Messel H., Crawford J., Yerbury M.J. 1978. Growth rates of Crocodylus porosus from Arnhem Land, Northern Australia. Australian Wildlife Research 5:385-399. DOI
Webb G.J.W., Britton A.R.C., Manolis S.C., Ottley B., Stirrat S. 2000. The recovery of Crocodylus porosus in the Northern Territory of Australia: 1971-1998. Pp. 195-234, in Crocodile Specialist Group IUCN (Eds.). Proceedings of the $15^{\text {th }}$ Working Meeting of the CSG-IUCN - The World Conservation Union, Gland.

Wilkinson P.M., Rhodes W.E. 1997. Growth rates of American alligators in coastal South Carolina. The Journal of Wildlife Management 61:397-402. DOI

Wilkinson P.M., Rainwater T.R., Woodward A.R., Leone E.H., Carter C. 2016. Determinate growth and reproductive lifespan in the American Alligator (Alligator mississippiensis): evidence from longterm recaptures. Copeia 104:843-852. DOI

Wood J., Patton T.M., Page R.B. 2017. Movement and overwinter survival of released captive-raised juvenile American alligators (Alligator mississipiensis) in Southeastern Oklahoma, USA. Herpetological Review 48:293-299.

Woodward A.R., Hines T.C., Abercrombie C.L., Nichols J.D. 1987 Survival of young American Alligators on a Florida lake. The Journal of Wildlife Management 51:931-937. DOI

Ziegler T., Olbort S. 2007. Genital structures and sex identification in crocodiles. Crocodile Specialist Group Newsletter 26:16-17. 